\title{
Queratitis Micótica: identificación de especies en Valparaíso
}

\author{
(Fungal Keratitis: identification of species in Valparaíso)
}

Rodrigo Cruz Ch.

Hospital Carlos van Buren, Infectología. Universidad de Valparaíso, Cátedra de Micología.

RECIBID0: 5-11-13

Correo electrónico: rodrigo.cruz@uv.cl

APROBAD0: 6-12-13

Palabras clave: queratitis, hongos, diagnósitco.

Key words: keratitis, fungi, diagnosis.

\section{RESUMEN}

Introducción: La queratitits micótica puede ser provocada por una amplia variedad de especies, tanto por hongos filamentosos como levaduras.

Objetivo: Conocer las especies involucradas en queratitits micótica durante el decenio 2003-2013 en la ciudad de Valparaíso.

Materiales y método: Se revisaron los casos de queratitis micótica diagnosticados durante el periodo 2003-2013 en la cátedra de Micología de la Universidad de Valparaíso. Las muestras fueron tomadas con tórulas estériles, las cuales fueron sembradas en agar sabouraud y una vez obtenido el desarrollo de las especies se traspasaron a medios de cultivo especiales. La identificación se realizó por morfofisiología y en el caso de Candida además por pruebas bioquímicas.

Resultados: Se diagnosticaron 10 pacientes con queratitis micótica, de ellos 6 fueron hombres. 8 pacientes tenían el antecedente de lesión traumática corneal. Las especies más frecuentes fueron Aspergillus fumigatus y Fusarium oxysporum. También se aislaron especies como Fusarium dimerum y Exophiala jeanselmei.

Conclusión: De los 10 casos de queratitis micótica diagnosticados, la mayoría tenía el antecedente de lesión traumática corneal. Los generos más aislados fueron Aspergillus y Fusarium.

\section{ABSTRACT}

Introduction: Fungal keratitis can be caused by a wide variety of species, either filamentous as yeast fungi.

Objective: To determine the species involved in fungal keratitis during the decade 2003-2013 in the city of Valparaiso.

Materials and Methods: The cases of fungal keratitis diagnosed in the department of Mycology, University of Valparaiso, were reviewed for the period 2003-2013. Samples were taken with sterile swabs, which were seeded in Sabouraud agar and after obtaining the development of species, were transferred to special culture media. Identification was performed by morphophysiology and in the case of Candida further biochemical tests.

Results: 10 patients were diagnosed with fungal keratitis, of which 6 were men. 8 patients had a history of traumatic corneal injury. The most frequent species were Aspergillus fumigatus and Fusarium oxysporum. Species Fusarium dimerum and Exophiala jeanselmei were also isolated.

Conclusion: Of the 10 cases of fungal keratitis diagnosed, most had a history of traumatic corneal injury. The most isolated genus were Aspergillus and Fusarium. 


\section{INTRODUCCIÓN}

La queratitis micótica (queratomicosis) es una infección de la córnea provocada por una amplia variedad de hongos. Afecta principalmente el epitelio y el estroma, aunque el endotelio y la cámara anterior del ojo pueden involucarse en una enfermedad mas gra$\mathrm{ve}(1)$.

Se le considera una enfermedad de las zonas rurales y se asocia principalmente a traumatismos con ramas, espinas u otros elementos vegetales. Sin embargo, otros factores de riesgo reportados incluyen cirugía ocular previa, enfermedad de la superficie ocular, el uso previo de corticoides (ya sea tópicos 0 sistémicos) y el uso de lentes de contacto $(1,2,3)$. Las especies incolucradas incluyen a hongos filamentosos pertenecientes a los géneros Fusarium, Aspergillus, Curvularia, Scedosporium y Paecilomyces, entre otros. El género Candida es el mas frecuente entre las levaduras $(4,5)$.

La identificación a nivel de especie es fundamental al momento de elegir un tratamiento, ya que la sensibilidad a los antifúngicos puede ser distinta y por lo tanto determinar un éxito o falla terapéutica (6).

El objetivo del presente trabajo es conocer las especies involucradasen queratitis micótica durante el decenio 2003-2013 en la ciudad de Valparáiso.

\section{MATERIALES Y MÉTODO}

Estudio descriptivo y retrospectivo. Se revisaron los casos de queratitis micótica diagnosticados durante el período 2003-2013 en la Cátedra de Micología de la Universidad de Valparaíso.

Criterios de inclusión: Pacientes con diagnóstico de queratitis micótica realizado por oftalmólogos de la quinta región de Valparaíso y con desarrollo de alguna especie fúngica en los cultivos.

Diagnóstico micológico: Las muestras fueron tomadas con tórulas estériles, las cuales se sembraron en agar sabouraud (glucosa 20 gr., peptona 10gr., agar 20 gr., cloranfenicol 0,25 gr., agua destilada $1000 \mathrm{ml}$.) inicialmente y una vez desarrollada la especie traspasadas a medios específicos.

Las especies de Aspergillus fueron sembradas en agar Malta (extracto de malta en polvo 20 gr., peptona 1 gr., glucosa 20 gr., agar 20gr., agua destilada 1000 ml.) y CYA (fosfato de potasio $1 \mathrm{gr}$., concentrado de Czapek $10 \mathrm{ml}$., extracto de levadura $5 \mathrm{gr}$., sucrosa 30 gr., agar 15 gr., agua destilada $1000 \mathrm{ml}$.), Fusarium en agar Clavel (Agar agua con hojas de clavel esteri- lizadas con hipoclorito de sodio durante 5 minutos y lavadas 3 veces en agua destilada estéril), Exophiala en agar PDA (Extracto de papa 20 gr., dextrosa 10 gr., agua destilada $1000 \mathrm{ml}$.) y Candida en CHROMagar Candida ${ }^{\circledR}$ (Becton Dickinson, Francia).

La identificación se realizó mediante morfofisiología y en el caso de Candida se realizó además pruebas bioquímicas con IDC32® (bioMérieux, Francia).

\section{RESULTADOS}

Se diagnosticaron 10 pacientes con queratitis micótica, de ellos 6 fueron hombres, con un promedio de edad de 45 años.

8 tenían el antecedente de lesión traumática corneal, 1 de ulcera asociada a lentes de contacto y 1 de trasplante de córnea.

Las especies más frecuentes fueron $A$. fumigatus (imagen 1) y F. oxysporum (imagen 2), sin embargo también se aislaron especies como F. dimerum (imagen 3) y E. jeanselmei (imagen4), tal como se muestra en la tabla 1.

Tabla 1. Especies aisladas en cultivos de córnea

\begin{tabular}{ll|}
\hline A. fumigatus & 3 \\
\hline A. flavus & 1 \\
\hline E. oxysporum & 2 \\
\hline F. solani & 1 \\
\hline f. dimerum & 1 \\
\hline E. jeanselmei & 1 \\
\hline C. albicans & 1 \\
\hline
\end{tabular}

\section{DISCUSIÓN}

La queratitis micótica representa una de las formas de queratitis más difíciles en su diagósitco y tratamiento, constituyendo un problema oftalmológico importante que puede llevar incluso a la pérdida de la visión $(5,6)$

Lesiones traumáticas con ramas, espinas u otros elementos de orígen vegetal no sólo pueden provocar úlceras o erosiones corneales, sino también contaminación con propágulos fúngicos que pueden repro- 
ducirse y generar una importante reacción inflamatoria y necrosis $(7,8)$. Estos datos coinciden con nuestro estudio, donde la mayor parte de los pacientes $(8 / 10)$ presentaron lesiones con ramas o espinas previo a la infección fúngica.

Factores ambientales como la humedad, lluvia y viento parecen tener relacion con la aparición de queratitis por hongos filamentosos y también podrían determinar las variaciones estacionales en los aislamientos de las especies. En un trabajo realizado en el Golfo de México, las queratitis por Curvularia spp. ocurrieron con más frecuencia durante los meses mas calurosos y húmedos de verano. En otro estudio realizado en Brasil se encontró una mayor incidencia cuando el
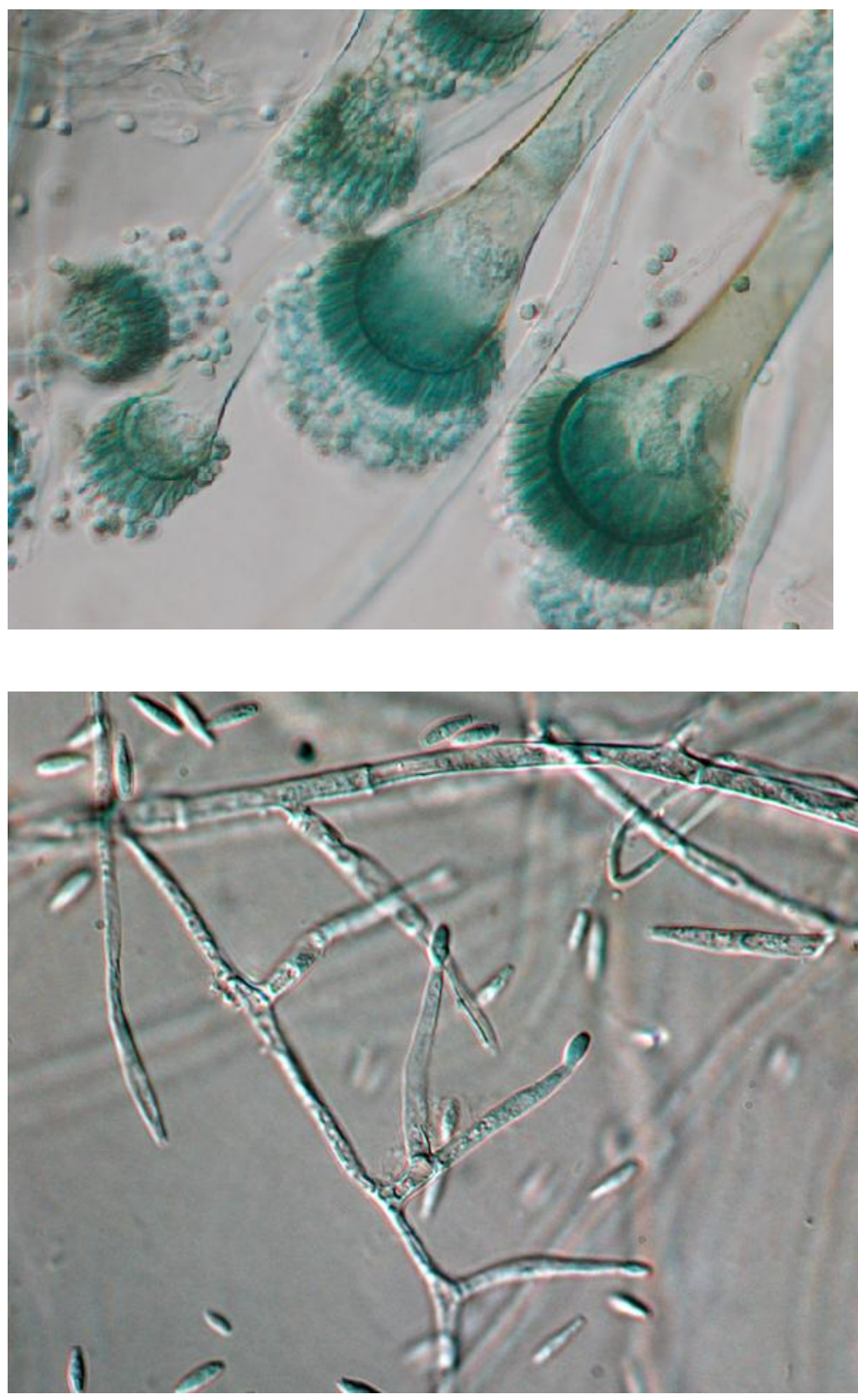

clima era mas seco y la actividad agrícola era más intensa (11). En nuestros casos, la infeccipón se distribuyó por igual en todos los meses del año.

Los hongos filamentosos como $F$. oxysporum y $F$. solani, junto a $A$. fumigatus son los que se reportan con mayor frecuencia $(6,12,13)$. Nuestro estudio coincide con datos publicados previamente, además de diagnosticar otras especies como F. dimerum y $E$. jeanselmei las que se aíslan con menor frecuencia.

Es importante recordar que para un buen tratamiento de una queratitits micótica es fundamental lograr identificar la especie, ya que estas pueden presentar resistencias distintas a los antifúngicos usados habitualmente (14).

Figura 1. Imagen microscópica de $A$. fumigatus. Tinción de Lactofenol con azul de algodón. 100 X. Se observan vesículas clavadas; vesículas uniseriadas estríctas con fiálides que cubren la mitad de ésta, dispuestas en forma paralela con el eje del estipe; conidios globosos o elipsoides, lisos a finamente rugosos de 2-3 $\mu \mathrm{m}$ de diámetro.

Figura 2. Imagen microscópica de $F$. oxysporum. Tinción de Lactofenol con azul de algodón. 100X. Microconidios ovoides con un tamaño de 5-12 x 2,3-3,5 $\mu \mathrm{m}$. Nacen de monofiálides laterales, cortas y anchas, afiladas hacia la punta. 

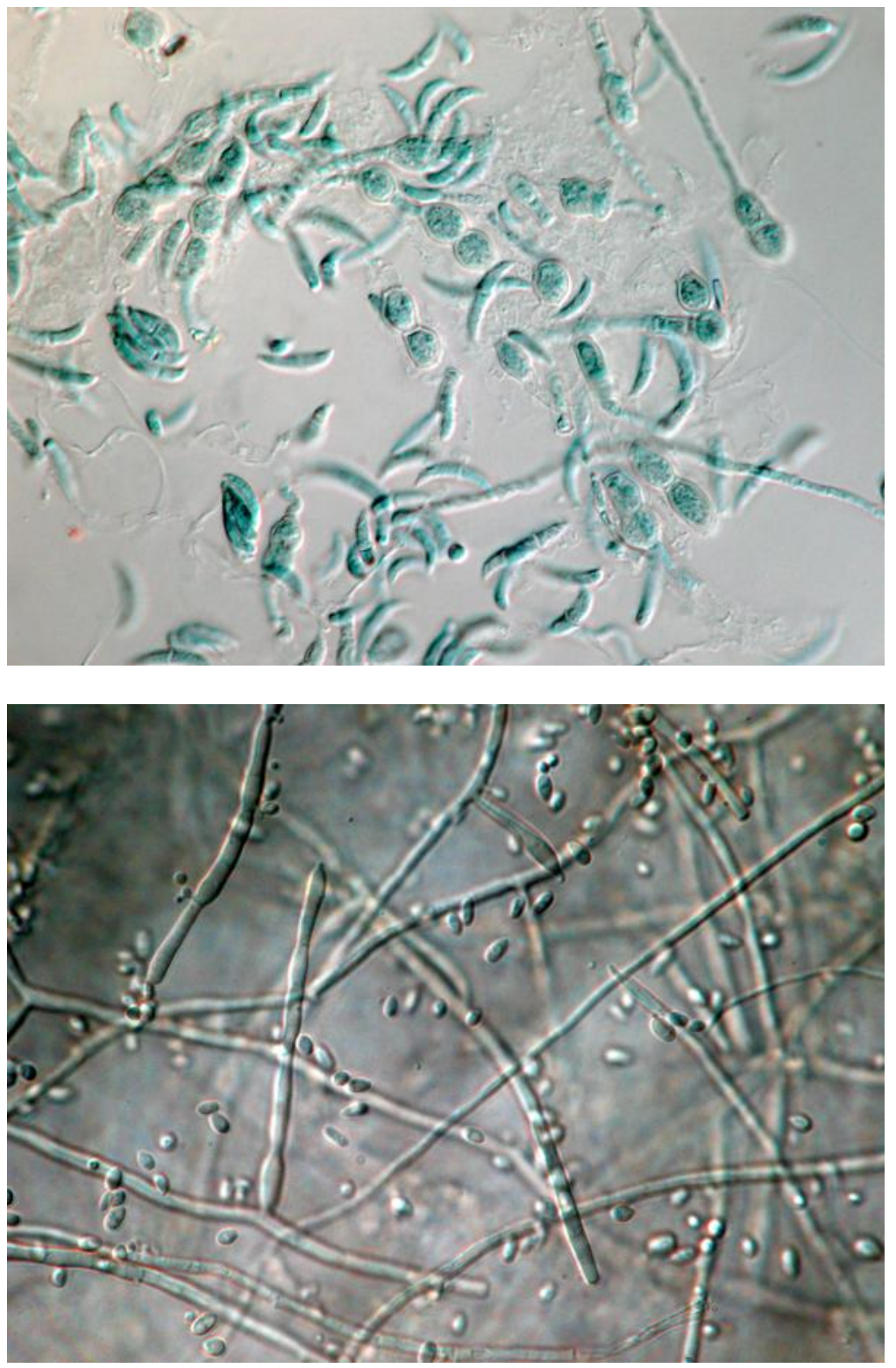

REFERENCIAS
Figura 3. Imagen microscópica de F.dimerum . Tinción de lactofenol con azul de algodón. 100X. Macroconidios curvados en su mayoría de 1-2 septos, con un tamaño de 5-25 x 1,5-4,2 $\mu \mathrm{m}$. Microconidios ausentes. Presencia de clamidosporas intercalares y terminales.

Figura4. Imagen microscópica de $E$. jeanselmei. Tinción de lactofenol con azul de algodón. 100X. Células conidiógenas en forma de cohete, con inconspicuas zonas aneladas. Conidios hialinos, lisos, de paredes delgadas, ampliamente elipsoidales, 2,6-5,9 x 1,2-2,5 $\mu \mathrm{m}$.
1. Sonal T.Fungal keratitis. Clinical Ophthalmology. 2011; 5: $275-279$.

2. Liesegang TJ, Forster RK. Spectrum of microbial keratitis in South Florida. Am J Ophthalmol. 1980;90:38-47.

3. Gopinathan U, Sharma S, Garg P, Rao GN. Review of epidemiological features, microbiological diagnosis and treatment outcome of microbial keratitis: experience of over a decade. Indian J Ophthalmol. 2009;57:273-279.

\section{Keay LJ, Gower EW, Iovieno A, Oechsler R, Alfonso E,} Matoba A, Colby K, et al. Clinical and microbiological characteristics of fungal keratitis in the United States, 20012007: a multicenter study. Ophthalmology 2011; 118: 920926.
5. Sun RL, Jones DB, Wilhelmus KR. Clinical characteristics and outcome of Candida keratitis. Am J Ophthalmol 2007; 143: 1043-1045.

6. Salim R, Runco R.Especies de Fusarium como agentes de queratitis micotica en adultos en Tucumán Argentina. Bol Micol. 2008;23 : 27 - 33.

7. Doczi I, Gyetvai T, Kredics L, Nagy E. Involvement of Fusarium spp. in fungal keratitis. Clinical Microbiology and Infection 2004;10:773-776.

8. Wong TY, Fong KS, Tan DT. Clinical and microbial spectrum of fungal keratitis in Singapore: a 5-year retrospective study. Int Ophthalmol. 1997;21:127-130. 
9. Leck AK, Thomas PA, Hagan M, Kaliamurthy J, Ackuaku E, John M, Newman MJ, et al. Aetiology of suppurative corneal ulcers in Ghana and south India, and epidemiology of fungal keratitis. Br J Ophthalmol 2002; 86: $1211-1215$.

10. Wilhelmus KR. Climatology of dematiaceous fungal keratitis. Am J Ophthalmol 2005; 140: 1156-1157.

11. Ibrahim MM, de Angelis R, Lima AS, Viana de Carvalho G, Ibrahim F, Tannus L, Bichuete M, et al. A new method to predict the Epidemiology of fungal keratitis by monitoring the sales distribution of antifungal eye drops. PLOS ONE 2012; 7: e33775.
12. Thomas P. Tropical ophthalmomycoses.In:Seal D,Pleyer U,eds. Ocular infection.2nd edn. New York: Informa Healthcare. 2007: 271-305.

13. Thomas PA, Kaliamurthy J. Mycotic keratitis: epidemiology, diagnosis and management. Clin Microbiol Infect. 2013; 19: 210-220.

14. Ansari Z, Miller D, Galor A. Current Thoughts in Fungal Keratitis: Diagnosis and Treatment. Curr Fungal Infect Rep. 2013; 7:209-218.

\section{CONFLICTO DE INTERESES}

El autor declara no tener conflicto de intereses. 